\title{
Clinical criteria for the application of percutaneous needle electrolysis in tendinopathies: An expert Consensus cocument and cross-sectional study among physical therapists
}

\author{
Fermín Valera Garrido ${ }^{1}$ Fernando Polidori ${ }^{2}$ Jerónimo Benavent Canet ${ }^{3}$ Francesc i Sicarrats Botet ${ }^{4}$ \\ Pablo Martínez Ramírez ${ }^{5}$ Sandra Calvo ${ }^{6}$ Javier Belsué Pastora ${ }^{6}$ Francisco Minaya Muñoz ${ }^{1}$
}

\footnotetext{
${ }^{1}$ MVClinic. Madrid, España. Universidad CEU San Pablo, Madrid. Getafe CF, Spain

${ }^{2}$ Kinesiología Polidori, Mendoza, Argentina

3 Fisio Global Sport, Valencia, Spain

${ }^{4}$ L'estudi Sport Vic, Barcelona. F.C.Wuhan (Superliga China), Wuhan, China

${ }^{5}$ Valencia Basket, Valencia, España. Fisiosport, Valencia, Spain

${ }^{6}$ Grupo de investigación iPhysio. Facultad de Ciencias de la Salud,

Universidad San Jorge. Campus Universitario, Zaragoza, Spain
}

Address for correspondence D. Fermín Valera Garrido, PT, MSc, PhD, Madrid, Spain (e-mail: ferminvalera@mvclinic.es).

Rev Fisioter Invasiva 2019;2:55-61.

\begin{abstract}
Keywords

- electrolisis

- invasive physiotherapy

- tendinopathies

Introduction Percutaneous needle electrolysis is a technique of invasive physical therapy which has been applied successfully in tendinopathies over the last decade. This study sought to explore the opinion and criteria employed by physical therapists who apply this technique in tendinopathies.

Material and Methods A cross-sectional study based on a survey of 15 questions to gather the sociodemographic characteristics of attendees and to examine four dimensions associated with the application of percutaneous needle electrolysis (indications, dosage, ultrasound-guidance, supporting therapies). The participants voted on the survey simultaneously after installing the "Votephone" App on their mobile phones or smartphones.

Results The study participants included 212 people who attended the CIFI 2018 conference and four experts. Of those who responded, $74.5 \%$ were men, who were mainly dedicated to clinical work (91.8\%), and were aged between 25 and 45 years (97.6\%). Electrolysis was used by $79 \%$ of respondents in their daily practice, for which $32.89 \%$ had over six years' experience. Percutaneous needle electrolysis was considered the therapy of choice in the treatment of tendinopathies for $91.03 \%$ of respondents, whereas $98.67 \%$ used it in situations of chronicity, and for tissue repair purposes (85\%). Of all people surveyed, 97.74\% considered that ultrasound guidance was essential for its application, employing intensities of between 2-4 mA (59.60\%) and combined with therapeutic exercise (77.78\%). Ultrasound in B mode (50.85\%) and palpation with the needle and reproduction of symptoms (47.46\%) are the criteria used to define the area of intervention.

Conclusions Percutaneous needle electrolysis is often used by physical therapists in chronic tendinopathies, applying high intensities (2-4 mA) aimed at repair of the damaged tissue. Attendees considered that the use of ultrasound for assessment and as a guide for the intervention is essential to guarantee a safe application and improve effectiveness. Percutaneous needle electrolysis is most commonly associated with therapeutic exercise.
\end{abstract}

received

December 16, 2019

accepted

December 17, 2019
DOI https://doi.org/

10.1055/s-0039-3402789. ISSN 2386-4591.
Copyright (e 2019 by Thieme Revinter

Publicações Ltda, Rio de Janeiro, Brazil
License terms

(ㄷ) (i) $\ominus$ (\$) 


\section{Introduction}

Tendons are dense and fibrous connective tissues, which play an essential role both in strength transmission as well as in the generation of joint movement. ${ }^{1}$ Tendinopathy is a term which refers to a complex multifactorial tendon pathology, characterized by pain, decreased function and structural alteration. $^{2}$

Most cases of tendinopathy are caused by overuse, as a result of repeated micro efforts repeated below the threshold of error, analogous to what happens due to fatigue in most materials when they are subjected to repetitive loading. ${ }^{1,3}$ Traumatic repetitive events, such as tendinopathies, represent more than $65 \%$ of work-related musculoskeletal disorders ${ }^{4}$ and are one of the most common damaging events in athletes, representing $30 \%$ of all the injuries related with "running" and with a prevalence of almost $40 \%$ in tennis players. $^{5}$

Among the wide range of treatments for a tendinopathy, ${ }^{6}$ in the last decade several therapeutic options have arisen such as percutaneous needle electrolysis, ${ }^{7}$ shock wave ther$a p y,{ }^{8}$ or infiltrations with platelet rich plasma. ${ }^{9}$ Percutaneous needle electrolysis is a minimally invasive technique which consists of the application of a galvanic current in the neuromusculoskeletal tissue via a solid, filiform and nonbeveled needle, which triggers a local inflammatory process, producing an increase of cell activity and thus enabling the repair of the affected tissue. ${ }^{7}$ Since the year 2008 until present, over 5.000 physical therapists are estimated to have received training in this technique, following the various existing methodologies and training programs, which has enabled the development of clinical evidence. According to the scientific literature, percutaneous needle electrolysis has proven to be effective for the treatment of tendinopathies of the patellar tendon, epicondyle tendon, rotator cuff or the adductor longus. ${ }^{7,10-12}$

The III International Conference on Invasive Physical Therapy (CIFI), was organized by the Scientific Society of Neuromusculoskeletal Invasive Physical Therapy (SOCIFIN), and held on October 27 and 28, 2018 in Valencia. This conference enabled the opportunity of joining expert physical therapists in a panel on the application of percutaneous needle electrolysis with clinical physical therapists with different years of experience in the application of the technique. The aim of the present study was to explore the opinion of experts and conference attendees regarding the use of percutaneous needle electrolysis in tendinopathies, its indications, dosage, the use of ultrasound and the use of supporting therapies, to establish clinical application criteria.

\section{Material and Methods}

\section{Study Design}

A cross-sectional study was conducted based on a survey of 15 questions directed to the attendees of the CIFI 2018. The survey was designed previously after a brainstorming session among physical therapists who had extensive clinical experience on the application of percutaneous needle electrolysis ( $>5$ years) and those who participated in the panel of experts. The physical therapists on the panel included: Jerónimo Benavent Canet, Fernando Polidori, Francesc Sucarrats i Botet and Fermín Valera Garrido, and was moderated by Pablo Martínez Ramírez. Of the 15 questions included in the survey, the first five were general questions to reflect the sociodemographic characteristics of attendees. The remaining questions were divided into four thematic blocks, followed by a debate on the responses of attendees after each question:

1. Indications. Situations in which percutaneous needle electrolysis is used, criteria and assessment tools. Questions 6-9.

2. Dosage. Aim of percutaneous needle electrolysis and dosage. Questions 10-12.

3. Ultrasound-guided nature of the technique. Use of ultrasound for the application of the technique and for determining the area of intervention. Questions 13-14.

4. Supporting therapies. Therapies that are combined with percutaneous needle electrolysis. Question 15.

The questions had single responses, except for questions $7,8,9,10,14$ and 15 , where a multiple response was allowed. After the responses of attendees to the survey, the experts intervened, providing their opinions and discussing whether or not they agreed to the responses obtained in the sample. The survey is available in Annex 1.

The questions and their possible responses were displayed on the auditorium screen using PowerPoint. The attendees casted their votes simultaneously, after installing the "Votephone" App on their mobile phones or smartphones.

\section{Statistical Analysis}

For the statistical analysis, all the surveys were considered, independent of whether or not they were responded in their entirety. The data were exported to an Excel sheet for subsequent analysis using the IBM SPSS statistics program version 23 .

\section{Results}

As the statistical analysis included all the surveys, irrespective of whether they had been responded to in their entirety, the total number of responses varied for the different questions featured in the survey. A total of 212 anonymous respondents participated in the survey.

\section{Survey Responses}

Of the total people surveyed, $74.5 \%$ were men, aged between 25 and 45 years (97.6\%) involved in clinical work (91.86\%). Furthermore, $79 \%$ used electrolysis in their daily practice, with three groups of experience regarding the application of the same (38.26\% less than 3 years' experience; $28.86 \%$ between 3 and 6 years; 32.89\% over 6 years). - Table 1 displays the sociodemographic characteristics of attendees.

\section{Indications}

Of the total number of people surveyed, $91.03 \%$ considered that percutaneous needle electrolysis is the therapy of choice for the treatment of tendinopathies. Regarding the 
Table 1 Sociodemographic characteristics of attendees extracted from questions 1-5

\begin{tabular}{|c|c|}
\hline Variables & n (\%) \\
\hline \multicolumn{2}{|l|}{ Sex (n) } \\
\hline Men & $102(74.5)$ \\
\hline Women & $35(25.5)$ \\
\hline \multicolumn{2}{|l|}{ Age (years) } \\
\hline $20-25$ & $12(7.1)$ \\
\hline $25-30$ & $41(24.26)$ \\
\hline $30-35$ & $42(24.85)$ \\
\hline $35-40$ & $44(26.04)$ \\
\hline $40-45$ & $17(10.06)$ \\
\hline $45-50$ & $9(5.33)$ \\
\hline $50-55$ & $0(0)$ \\
\hline $55-60$ & $0(0)$ \\
\hline$>60$ & $4(2.37)$ \\
\hline \multicolumn{2}{|l|}{ Field of work (n) } \\
\hline Clinical & 158 (91.86) \\
\hline Teaching & $3(1.74)$ \\
\hline Research & $3(1.74)$ \\
\hline Management & $1(0.58)$ \\
\hline Others & $7(4.07)$ \\
\hline \multicolumn{2}{|l|}{$\begin{array}{l}\text { Use of percutaneous needle electrolysis } \\
\text { in the clinic }(n)\end{array}$} \\
\hline Yes & $143(79.01)$ \\
\hline No & 38 (20.99) \\
\hline \multicolumn{2}{|l|}{$\begin{array}{l}\text { Years of experience with percutaneous } \\
\text { needle electrolysis (years) }\end{array}$} \\
\hline$<3$ years & $57(38.26)$ \\
\hline $3-6$ years & $43(28.86)$ \\
\hline$>6$ years & $49(32.89)$ \\
\hline
\end{tabular}

Descriptive statistical data.

$\mathrm{n}$ : number of subjects.

clinical situations where the attendees use percutaneous needle electrolysis, acute tendinopathy received 99 votes (65.12\%) whereas chronic tendinopathy received 150 votes (98.67\%). Regarding the criteria which the attendees used to determine the indication of percutaneous needle electrolysis, functional criteria received a total of 108 votes $(72.47 \%)$ and structural criteria received 128 votes $(85.89 \%)$. To evaluate tendon structure, ultrasound received 140 votes in total (97.91\%) and elastography received 37 votes (25.88\%). Only one person did not use any of these tools $(0.70 \%)$ (-Table 2 ).

\section{Dosage}

Regarding the main objective sought when applying percutaneous needle electrolysis on a tendon, analgesia received 18 votes (15\%), whereas repair of the structure received 102
Table 2 Frequency of votes for the "Indications" Block

\begin{tabular}{|c|c|}
\hline Question & n (\%) \\
\hline $\begin{array}{l}\text { Q.6. Do you consider that percutaneous } \\
\text { needle electrolysis is a therapy of } \\
\text { choice for tendinopathies? }\end{array}$ & \\
\hline Yes & $142(91.03)$ \\
\hline No & $14(8.97)$ \\
\hline $\begin{array}{l}\text { Q.7. In what clinical situations do you use } \\
\text { percutaneous needle electrolysis? } \\
\text { (multiple response) }\end{array}$ & \\
\hline Acute tendinopathy & $2(1.31)$ \\
\hline Chronic tendinopathy & $53(34.86)$ \\
\hline Acute + chronic & $97(63.81)$ \\
\hline $\begin{array}{l}\text { Q.8. What criteria do you use to determine } \\
\text { the indication of percutaneous needle } \\
\text { electrolysis? (multiple response) }\end{array}$ & \\
\hline Functional & $21(14.09)$ \\
\hline Structural & $41(27.51)$ \\
\hline Functional + structural & $87(58.38)$ \\
\hline $\begin{array}{l}\text { Q.9. What tools do you use to evaluate } \\
\text { the tendon structure? } \\
\text { (multiple response) }\end{array}$ & \\
\hline Ultrasound & $102(71.33)$ \\
\hline Elastography & $1(0.70)$ \\
\hline Thermography & $1(0.70)$ \\
\hline Ultrasound + elastography & $32(22.38)$ \\
\hline Ultrasound + thermography & $2(1.40)$ \\
\hline $\begin{array}{l}\text { Ultrasound + elastography + } \\
\text { thermography }\end{array}$ & $4(2.80)$ \\
\hline None & $1(0.70)$ \\
\hline
\end{tabular}

Descriptive statistical data.

$\mathrm{n}$ : Number of votes.

votes (85\%). The selected intensity for a degenerated tendon with a simple sheath is 2-4 milliamperes (mA), receiving 90 votes (59.60\%) whereas the use of $4 \mathrm{~mA}$ received 2 votes (1.32\%). Neovascularization was considered the target tissue according to 84 votes (59.15\%) (-Table 3).

\section{Ultrasound-guided Nature of the Technique}

Of the total people surveyed, $97.74 \%$ (130 votes) considered that ultrasound guidance was essential for applying percutaneous needle electrolysis, whereas $1.50 \%$ ( 2 votes) and $0.75 \%$ ( 1 vote) considered it essential only for deep structures that are difficult to palpate and only in risk areas, respectively. To determine the area of intervention, once the affected area is determined using ultrasound and clinical tests, B mode received 30 votes (50.85\%), palpation with the needle and reproduction of symptoms received 28 votes (47.46\%) and elastography received 1 vote (1.69\%). None of the people surveyed used several methods to determine the area of intervention, simultaneously. (-Table 4). 
Table 3 Frequency of votes for the "Dosage" block

\begin{tabular}{|l|l|}
\hline Question & $\mathbf{n ~ ( \% )}$ \\
\hline $\begin{array}{l}\text { Q.10. What objective are you seeking } \\
\text { with percutaneous needle } \\
\text { electrolysis in a tendon? } \\
\text { (multiple response) }\end{array}$ & \\
\hline Analgesia & $18(15)$ \\
\hline Repair of the structure & $102(85)$ \\
\hline Analgesia + repair of the structure & $0(0)$ \\
\hline $\begin{array}{l}\text { Q.11. What intensity would you use in a } \\
\text { tendon with a simple sheath } \\
\text { with degeneration? }\end{array}$ & \\
\hline 0.3-1 mA & $19(12.58)$ \\
\hline 1-2 mA & $40(26.49)$ \\
\hline 2-4 mA & $90(59.60)$ \\
\hline$>4 \mathrm{~mA}$ & $2(1.32)$ \\
\hline $\begin{array}{l}\text { Q.12. Do you consider neovascularization } \\
\text { as being a target tissue? }\end{array}$ & $84(59.15)$ \\
\hline Yes & $58(40.85)$ \\
\hline No & \\
\hline
\end{tabular}

Descriptive statistical data.

$\mathrm{n}$ : Number of votes; mA: milliamperes.

Table 4 Frequency of votes for the "Ultrasound-guided nature of the technique" block

\begin{tabular}{|l|l|}
\hline Question & $\mathbf{n ~ ( \% )}$ \\
\hline $\begin{array}{l}\text { Q.13. Do you consider that ultrasound } \\
\text { guidance is essential for performance } \\
\text { of the electrolysis technique? }\end{array}$ & $130(97.74)$ \\
\hline Always & $2(1.50)$ \\
\hline $\begin{array}{l}\text { Only in deep structures that are } \\
\text { difficult to palpate }\end{array}$ & $1(0.75)$ \\
\hline $\begin{array}{l}\text { Only in areas at risk } \\
\text { Q.14. Once the affected area is } \\
\text { and clinical tests, how do you } \\
\text { determine the area of } \\
\text { intervention? (multiple response) }\end{array}$ & \\
\hline $\begin{array}{l}\text { Determining the most affected } \\
\text { site in B mode }\end{array}$ & $30(50.85)$ \\
\hline With assistance of elastography & $1(1.69)$ \\
\hline $\begin{array}{l}\text { Via needle palpation and reproduction } \\
\text { of symptoms }\end{array}$ & $28(47.46)$ \\
\hline
\end{tabular}

Descriptive statistical data.

$\mathrm{n}$ : Number of votes.

\section{Supporting Therapies}

The therapy which most people used in combination with percutaneous needle electrolysis was therapeutic exercise (28 votes; $77.78 \%$ ), followed by neuromodulation (5 votes; 13.89\%) and diathermia (3 votes; $8.33 \%$ ) (-Table 5).
Table 5 Frequency of votes for the "Supporting therapies" block

\begin{tabular}{|l|l|}
\hline Question & $\mathbf{n ~ ( \% )}$ \\
\hline $\begin{array}{l}\text { Q.15. In your clinical experience, what } \\
\text { therapy has given you good results } \\
\text { when combined with electrolysis? } \\
\text { (multiple response) }\end{array}$ & $28(77.78)$ \\
\hline Therapeutic exercise & $0(0)$ \\
\hline High voltage & $0(0)$ \\
\hline Microcurrents & $0(0)$ \\
\hline High power laser & $5(13.89)$ \\
\hline Neuromodulation & $3(8.33)$ \\
\hline Diathermia & \\
\hline
\end{tabular}

Descriptive statistical data.

$\mathrm{n}$ : Number of votes.

\section{Intervention by Experts}

After viewing the results of the votes, the experts expressed their agreement with most responses made by the public, although they clarified that they use percutaneous electrolysis preferably in chronic tendinopathies with the main objective of improving the damaged structure. In many cases, the subject presents a degenerated tendon in the reactive phase (inflammatory), which means a new flare up of the symptoms on a tendon with defined structural changes.

All experts highlighted the importance of ultrasound to evaluate the tendon and as a guide for the intervention to guarantee a safe application that is as effective as possible. In addition to B Mode and Doppler, some experts recommended the use of elastography as a tool that provides an added value as it identifies the areas of tendon degeneration. Regarding neovascularization, it is a therapeutic objective depending on its localization and quantity, therefore, only small, clinically relevant sites are the target tissue, with regular exercise being the initial treatment for tendinopathies displaying wide patterns of neovascularization. The change in neovascularization was considered an indicator of tendon improvement, together with echotexture and echogenicity changes. The thickening was not considered a finding that commonly changes with percutaneous needle electrolysis treatment. Together with ultrasound guide, palpation with the needle and reproduction of symptoms were considered essential for experts to confirm the target tissue.

Most experts chose high intensities (2-4 mA) to stimulate repair of the affected tendon, stressing the importance of differentiating between tendons with a simple sheath and those with a double sheath. They also indicated that, depending on the target tissue, intensity and time parameters should be adjusted. Thus, their experience was that, at low intensities the effect is mainly analgesic.

Despite an increase in the number and quality of scientific studies in recent years, future research is necessary to clarify and confirm the results obtained.

Regarding combined treatments, the experts considered therapeutic exercise as a means for stimulating the tissue of 
newly formed collagen. They considered that exercise should always be associated with electrolysis, however not always eccentric exercise, having to adapt the loading to the type of tendon and patient.

According to the clinical experience of the experts, percutaneous needle electrolysis is an effective technique in chronic tendinopathy, provided it is applied with appropriate methodology, which must integrate clinical and scientific evidence. This technique presents a very high cost-effectiveness, and its tolerance is similar to other invasive techniques used in physical therapy, such as dry needling.

\section{Conclusions}

The majority of physical therapists who use percutaneous needle electrolysis consider that chronic tendinopathy can benefit from this technique by applying current intensities of between $2-4 \mathrm{~mA}$, as long as there is a functional and structural relationship to justify this.

Ultrasound is essential, both for assessment purposes, and as a guide for the intervention. Its use and the reproduction of the patient's symptoms during examination with the needle are the criteria which are most often used to determine the area of intervention. Besides, therapeutic exercise is an essential tool for supporting the effectiveness of treatment.

Percutaneous needle electrolysis is a technique with positive clinical results which is being continuously developed and which requires further research studies to clarify further details regarding its application, as well as to compare it with other techniques.

The key for achieving optimal results is based on the methods employed which should be based on clinical reasoning, integrating experience with scientific evidence.

\section{Conflict of Interests and Source of Funding}

The authors declare no conflicts of interest nor commercial involvements with a direct financial interest in the results of this research.

\section{Acknowledgments}

To all the physical therapists who participated in the Fire Debates on Percutaneous Needle Electrolysis of the CIFI 2018 in Valencia.

\section{References}

1 Riley G. Chronic tendon pathology: molecular basis and therapeutic implications. Expert Rev Mol Med 2005;7(05):1-25

2 Khan KM, Cook JL, Bonar F, Harcourt P, Åstrom M. Histopathology of common tendinopathies. Update and implications for clinical management. Sports Med 1999;27(06):393-408

3 Dirks RC, Warden SJ. Models for the study of tendinopathy. J Musculoskelet Neuronal Interact 2011;11(02):141-149

4 Barr AE, Barbe MF, Clark BD. Work-related musculoskeletal disorders of the hand and wrist: epidemiology, pathophysiology, and sensorimotor changes. J Orthop Sports Phys Ther 2004;34(10):610-627

5 Federer AE, Steele JR, Dekker TJ, Liles JL, Adams SB. Tendonitis and Tendinopathy: What are they and how do they evolve? Foot Ankle Clin 2017;22(04):665-676

6 Everhart JS, Cole D, Sojka JH, et al. Treatment Options for Patellar Tendinopathy: A Systematic Review. Arthroscopy 2017;33(04): 861-872

7 Valera-Garrido F, Minaya-Muñoz F, Medina-Mirapeix F. Ultrasound-guided percutaneous needle electrolysis in chronic lateral epicondylitis: short-term and long-term results. Acupunct Med 2014;32(06):446-454

8 Mani-Babu S, Morrissey D, Waugh C, Screen H, Barton C. The effectiveness of extracorporeal shock wave therapy in lower limb tendinopathy: a systematic review. Am J Sports Med 2015;43(03):752-761

9 Zhou Y, Wang JHC. PRP Treatment Efficacy for Tendinopathy: A Review of Basic Science Studies. Biomed Res Int 2016;2016;

10 Abat F, Diesel WJ, Gelber PE, Polidori F, Monllau JC, SanchezIbañez JM. Effectiveness of the Intratissue Percutaneous Electrolysis (EPI $\left.{ }^{\circledR}\right)$ technique and isoinertial eccentric exercise in the treatment of patellar tendinopathy at two years follow-up. Muscles Ligaments Tendons J 2014;4(02):188-193

11 Arias-Buriá JL, Truyols-Domínguez S, Valero-Alcaide R, SalomMoreno J, Atín-Arratibel MA, Fernández-De-Las-Penãs C. Ultrasound-Guided Percutaneous Electrolysis and Eccentric Exercises for Subacromial Pain Syndrome: A Randomized Clinical Trial. Evidence-based Complement Altern Med 2015;2015;

12 Moreno C, Mattiussi G, Núñez FJ. Therapeutic results after ultrasoundguided intratissue percutaneous electrolysis $(\mathrm{EPI} \Re)$ in the treatment of rectus abdominis-related groin pain in professional footballers: a pilot study. J Sports Med Phys Fitness 2016;56(10):1171-1178 


\section{Annexes}

\section{Annex 1. Survey Directed at the Conference Attendees}

- Question 1. Indicate your sex
1. Man
2. Woman

- Question 2. Indicate your age
1. 20-25 years
2. 25-30 years
3. $30-35$ years
4. $35-40$ years
5. $40-45$ years
6. $45-50$ years
7. $50-55$ years
8. 55-60 years
9. Over 60 years

- Question 3. Indicate your field of work
1. Clinical
2. Teaching
3. Research
4. Management
5. Other

- Question 4. Do you regularly use percutaneous needle electrolysis in your daily practice?

1. Yes

2. No

- Question 5. How many years' experience do you have in the application of percutaneous needle electrolysis?
1. Less than 3 years
2. 3-6 years
3. Over 6 years

\section{Block 1. Indications}

- Question 6. Do you consider that percutaneous needle electrolysis is a therapy of choice for tendinopathies? 1. Yes

2. No

- Question 7. In what clinical situations do you use percutaneous needle electrolysis? (Possible multiple response)

1. Acute tendinopathy

2. Chronic tendinopathy

- Question 8. What criteria do you use to determine the indication of percutaneous needle electrolysis (Possible multiple responses)
1. Functional
2. Structural

- Question 9. What tools do you use to evaluate the tendon structure? (Possible multiple responses)

1. Ultrasound (B mode, Doppler)

2. Elastography

3. Thermography

4. None 


\section{Block 2. Dosage}

- Question 10. What objective are you seeking with percutaneous needle electrolysis in a tendon? (Possible multiple responses)

1. Analgesia

2. Repair of the structure

- Question 11 . What intensity would you use in a tendon with a simple sheath with degeneration?

1. $0.3-1 \mathrm{~mA}$

2. $1-2 \mathrm{~mA}$

3. $2-4 \mathrm{~mA}$

4. Over $4 \mathrm{~mA}$

- Question 12. Do you consider neovascularization as being a target tissue?

1. Yes

2. No

\section{Block 3. Ultrasound-guided Nature of the Technique}

- Question 13. Do you consider that ultrasound guidance is essential for performance of the electrolysis technique?

1. Always

2. Only in deep structures that are difficult to palpate

3. Only in areas at risk

- Question 14. Once the affected area is determined using ultrasound and clinical tests, how do you determine the area of intervention? (Possible multiple responses)

1. Determining the most affected site in B mode

2. With the help of elastography

3. Via needle palpation and reproduction of symptoms

\section{Block 4. Supporting Therapies}

- Question 15. In your clinical experience, what therapy has given you good results when combined with electrolysis? (Possible multiple response)

1. Therapeutic exercise

2. High voltage

3. Microcurrents

4. High power laser

5. Neuromodulation

6. Diathermia 